\title{
Effect of hyperbaric oxygen on experimental syphilis in the rabbit
}

\author{
E. I. GRIN, M. NADAŽDIN, AND M. ŠVOB
}

Institute of Dermato-Venereology, Sarajevo, Yugoslavia

It is generally accepted that Treponema pallidum is a strict anaerobe requiring a very low environmental oxygen reduction potential and to which oxygen is highly toxic. On this assumption investigations have been carried out to explore how far pure oxygen under increased pressure might be effective against experimental syphilis in the rabbit.

The inhibitory and toxic effect of hyperbaric oxygen (HBO) on bacterial growth in culture media (anaerobic and aerobic) has been recognized in various experiments (Boerema and Groeneverd, 1970; Chesney, Turney, and Halley, 1928; Hardy, 1969). However, evidence is largely lacking that this inhibitory or lethal effect can be adequately reproduced in vivo in humans or in experimental animals because the use of $\mathrm{HBO}$ is limited in vivo as prolonged exposure and high tension causes poisoning.

Breathing pure oxygen under hyperbaric conditions at approximately 2.5 atmospheres absolute (that usually used in our experiments) results in full chemical saturation of haemogloblin and in a substantial increase in the amount of oxygen in physical solution in the plasma (a rise of about $6 \mathrm{ml} . / 100 \mathrm{ml}$. blood).

It was reasonable to suppose that this high tension of pure oxygen and in consequence the increased oxygen supply of the tissues in infected animals might have some toxic or other effect on the anaerobic treponemes and alter the natural course of infection.

\section{Methods and material}

For hyperbaric oxygenation in our investigations the experimental hyperbaric system (Vickers Limited, London) was used with the maximum working pressure of four atmospheres absolute and the maximum oxygen flow of $301 . / \mathrm{min}$.

The investigations were carried out, including

Received for publication November 29, 1972

Address: P.O.B. 137, Sarajevo, Yugoslavia control tests, on 64 rabbits which were inoculated with the Nichols strain (testicularly 36 , intravenously 18 , and cutaneously 10). Of the inoculated rabbits 29 were lost, mostly during or shortly after the exposures to $\mathrm{HBO}$, particularly if they had been exposed longer to higher oxygen pressures.

The inoculated animals were usually exposed to $\mathrm{HBO}$ at 2 to 3 ATA for 1 to 5 days or more by exposures of 2 to $4 \mathrm{hrs}$ at intervals of 2 to $4 \mathrm{hrs}$. The exposure varied from one to six times daily and the total exposure time from 4 to $30 \mathrm{hrs}$.

The observation of infected animals after termination of the experiments lasted up to 6 months.

\section{Results}

(1) In the group of experimental animals inoculated intratesticularly and 5 days later exposed to $\mathrm{HBO}$ (2 ATA, for $2 \mathrm{hrs}$ repeated four times daily at $2-\mathrm{hr}$ intervals), clinical manifestations in the inoculated testicles, if not already present, were postponed for about 4 weeks. However, if clinical signs (beginning of swelling and inflammation) were established before the exposure to $\mathrm{HBO}$ (i.e. 5 days after inoculation), there was first an intensification of inflammation and a few days later a return to normal. As a rule about 30 days after the termination of hyperbaric oxygenation, the infected testicles became enlarged, swollen, and hard, and soon necrosed and ulcerated.

Darkground examination for $T$. pallidum in these testicles at the beginning of hyperbaric oxygenation, and particularly at the end of the course, generally showed first a reduction in the number of the organisms and usually later a complete absence. However, this absence of treponemes was transient, because in a few days (usually 8) the darkfield examination again became positive.

Regarding the serological findings in this group of experiments, there was no difference between the experimental and control animals which were not exposed to $\mathrm{HBO}$ in respect of the onset of positive VDRL tests, but in the HBO exposed animals the 
titre later usually became higher than in the control group at the same period of time after inoculation.

(2) The next group of experiments relate to intratesticular inoculation of rabbits which were exposed to $\mathrm{HBO}(4 \times 4 \mathrm{hrs}$ at 2 ATA with intervals of $2 \mathrm{hrs}-$ total exposure time $16 \mathrm{hrs}$ ) 30 days after inoculation.

In this group the $\mathrm{HBO}$ produced no special effect on the exposed animals and no essential difference could be observed in the further course of the infection between the exposed and control animals. Exceptionally, shortly after exposure to $\mathrm{HBO}$, a transient increased inflammation of the infected testicle occurred.

(3) In these experiments it was investigated whether the infection could be prevented or aborted when the exposure to HBO took place immediately after intravenous inoculation of the experimental animals.

The intravenous inoculation was carried out with $1 \mathrm{ml}$. of Treponema pallidum Nichols strain suspen$\operatorname{sion}\left(6 \times 10^{7}\right)$.

The exposure to $\mathrm{HBO}$ was varied as follows:

(a) $4 \mathrm{hrs}$ continuously at 3 ATA (total $4 \mathrm{hrs)}$

(b) $3 \mathrm{hrs}$ at 2 ATA daily for 10 days (total $30 \mathrm{hrs)}$

(c) $4 \times 4 \mathrm{hrs}$ at intervals of $2 \mathrm{hrs}$ (total $16 \mathrm{hrs}$ ).

In all the infected animals, regardless of the scheme of exposure to $\mathrm{HBO}, T$. pallidum-positive skin lesions developed on average 3 to 4 weeks after inoculation, analogous to the control animals which were not exposed to HBO.

There was also no difference in regard to the onset of positive serology except that in animals exposed to HBO a higher titre developed at the beginning than in the control animals, but later in the course of the infection this difference disappeared.
(4) When the tintravenously inoculated animals were exposed to $\mathrm{HBO}(7 \times 2 \mathrm{hrs}$ at 3 ATA with intervals of $2 \mathrm{hrs}$; total $14 \mathrm{hrs}$ ) near the end of the incubation period ( 20 days after inoculation), the development of skin lesions was postponed for about 14 days (6 weeks after inoculation) in comparison to the non-exposed animals inoculated the same day with the same suspension of treponemes.

(5) When the skin lesions had already developed (Fig. 1), and the experimental animal was then exposed to HBO ( $2 \frac{1}{2}$ hrs at 2.5 ATA daily for 10 days-total $25 \mathrm{hrs}$ ) a well-marked diminution of the skin lesions after intravenous inoculation was seen and they usually disappeared after a few exposures (Fig. 2). This was in contrast to the animals not exposed to $\mathrm{HBO}$, in which the skin lesions showed further progression (Fig. 3). However, the darkfield examination was usually positive, even though a distinct improvement in the clinical condition could be observed in the animals which were exposed to HBO.

(6) In latent syphilis no influence of $\mathrm{HBO}$, either clinical or serological, could be seen during the time of observation (6 mths).

\section{HISTOPATHOLOGY}

The histological investigations were of skin lesions in experimental animals which were infected by different routes and exposed to hyperbaric oxygenation. The biopsies were taken before and at different times after exposure to HBO and compared with the histology of control animals which were inoculated in the same way and with the same suspension of $T$. pallidum, but not exposed to $\mathrm{HBO}$.

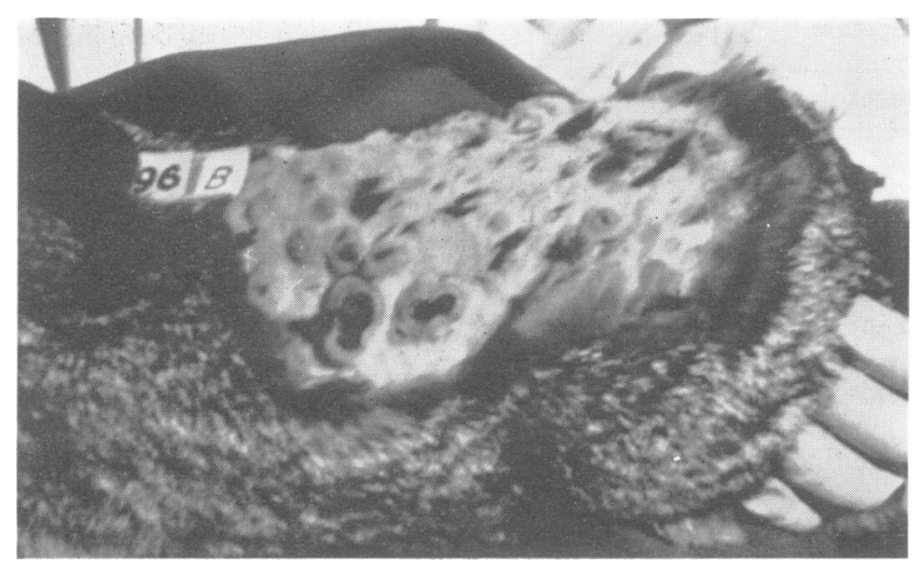

FIG. 1 Skin lesions in a syphilitic rabbit inoculated intravenously before exposure to $\mathrm{HBO}$ 
(1) After intradermal inoculation, biopsies were taken from the skin lesions 15 days after inoculation and the animal then exposed to HBO $(4 \times 2 \mathrm{hrs}$ daily at 2 ATA for 3 days-total exposure time $24 \mathrm{hrs}$ ).

The biopsies for histological examination in the exposed and control animals were taken after 8, 16, and $24 \mathrm{hrs}$, and on the 15th and 30th days.

(2) After intravenous inoculation, the experiment started 4 weeks later when skin lesions had already developed and the animals were then exposed to HBO (3 ATA $3 \mathrm{hrs}$ daily for 2 days-total $6 \mathrm{hrs).}$

Biopsies for histological examination in the exposed and control animals were performed before, and on the first and second day immediately after exposure to HBO.

The histological preparations were stained with haematoxylin and eosin, Van Gieson, and various special stains for histochemical analysis which will be described in detail elsewhere.

\section{HISTOPATHOLOGICAL FINDINGS}

The histopathological findings before exposure to HBO were typical of early skin lesions in experi- mental rabbit syphilis, with developing infiltration located particularly around the vessels and composed mainly of lymphocytes, 'pseudo-eosinophil', and plasma cells (Fig. 4) and proliferation and swelling of the endothelial cells with thickening and invasion of the walls of blood vessels (Fig. 5) leading to partial or complete obliteration of the lumina resulting in foci of necrosis.

After exposure to $\mathrm{HBO}$, even after $8 \mathrm{hrs}$ exposure at 2 ATA, the histopathological picture had changed. Cellular infiltration was composed mostly of plasma cells (Fig. 6) and the proliferation and swelling of endothelial cells of capillaries and blood vessels were markedly reduced so that their lumina became clear (Fig. 7) and the walls less thickened and almost normal in appearance. The same could be achieved after $3 \mathrm{hrs}$ ' exposure to HBO at 3 ATA.

Especially after a second exposure of $3 \mathrm{hrs}$ at $3 \mathrm{ATA}$ or 16 to $24 \mathrm{hrs}$ after exposure at $2 \mathrm{ATA}$, the polymorphous cell infiltration changed and plasma cells predominated; also cells in division appeared in the infiltrate which seemed to belong to the same group of mononuclear cells (Fig. 8, overleaf).

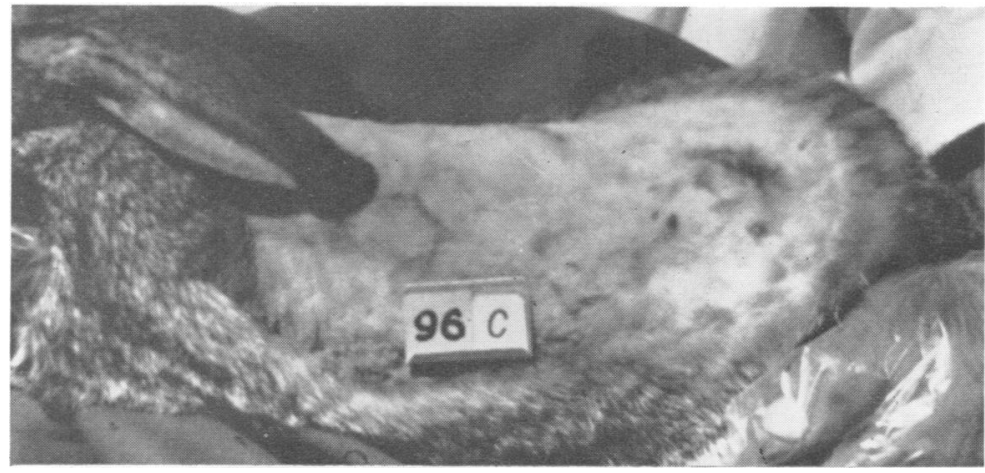

FIG. 2 Same rabbit as in Fig 1, but after exposure to $\mathrm{HBO}$ (3 weeks later)

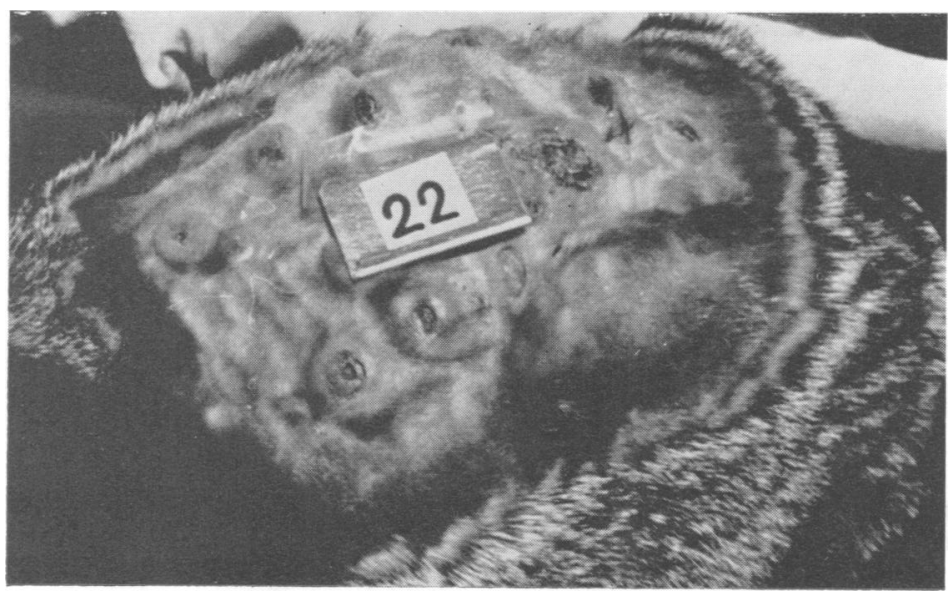

FIG. 3 Skin lesions in a control rabbit not exposed to $\mathrm{HBO}$ 


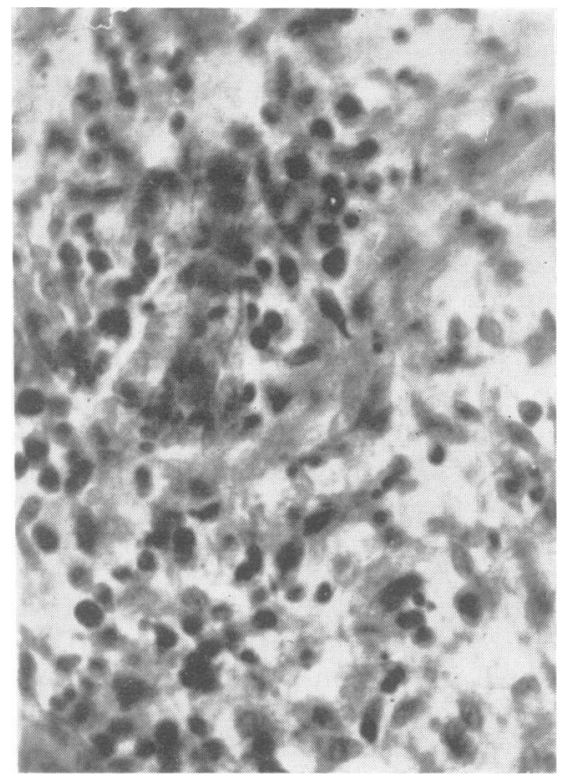

FIG. 4 Biopsy of a skin lesion from a syphilitic rabbit before exposure to $H B O$. Diffuse polymorphous infiltration. $\times 400$

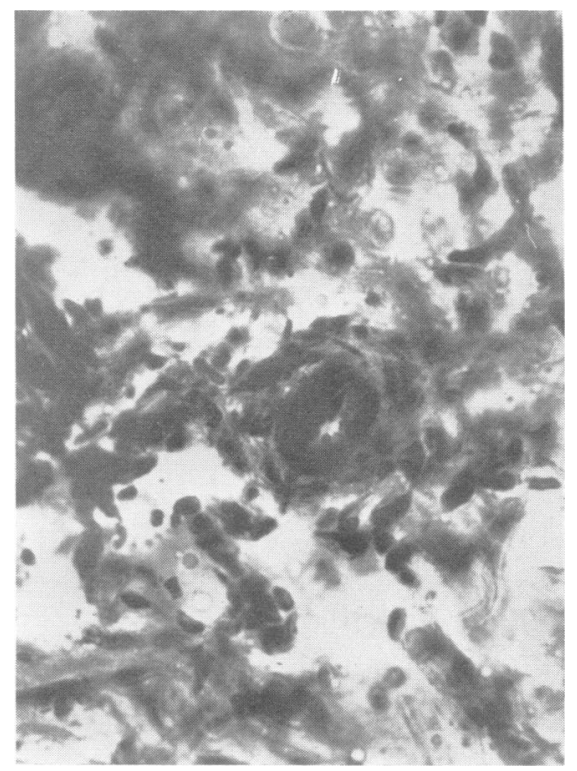

FIG. 5 Biopsy of a skin lesion from a syphilitic rabbit before exposure to $H B O$. Typical thickening of blood vessels. $\times 400$

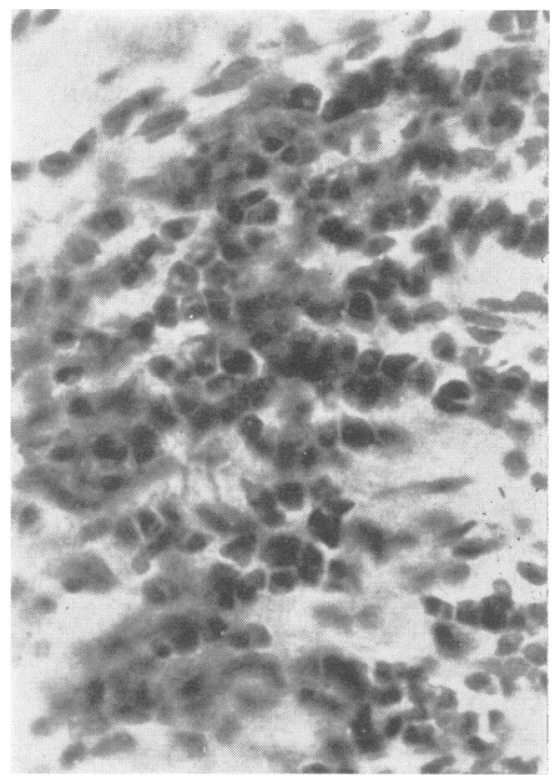

FIG. 6 Cellular infiltration composed mostly of plasma cells in a biopsy of a skin lesion in a syphilitic rabbit exposed to $H B O$ twice for 4 hrs at $2 A T A$. $\times 400$

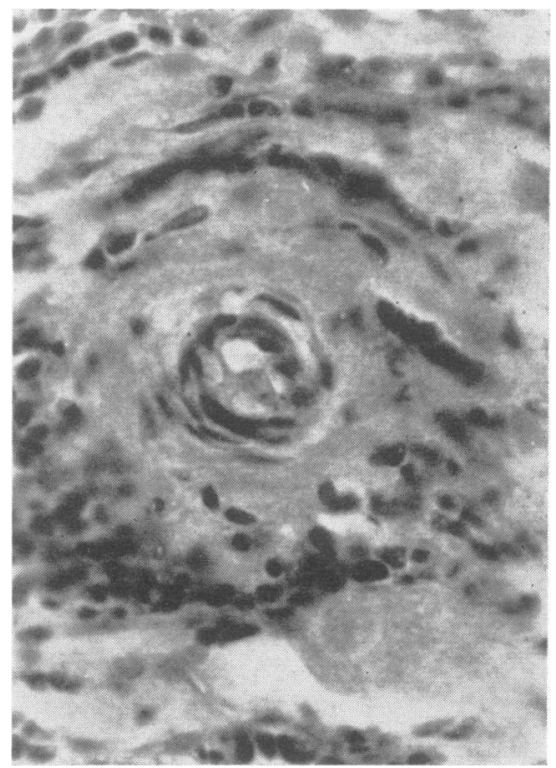

FIG. 7 Biopsy of a skin lesion from a syphilitic rabbit after exposure to $H B O$ four times for $2 \mathrm{hrs}$ at 2 AT A. Normalization of pathological vascular changes. 


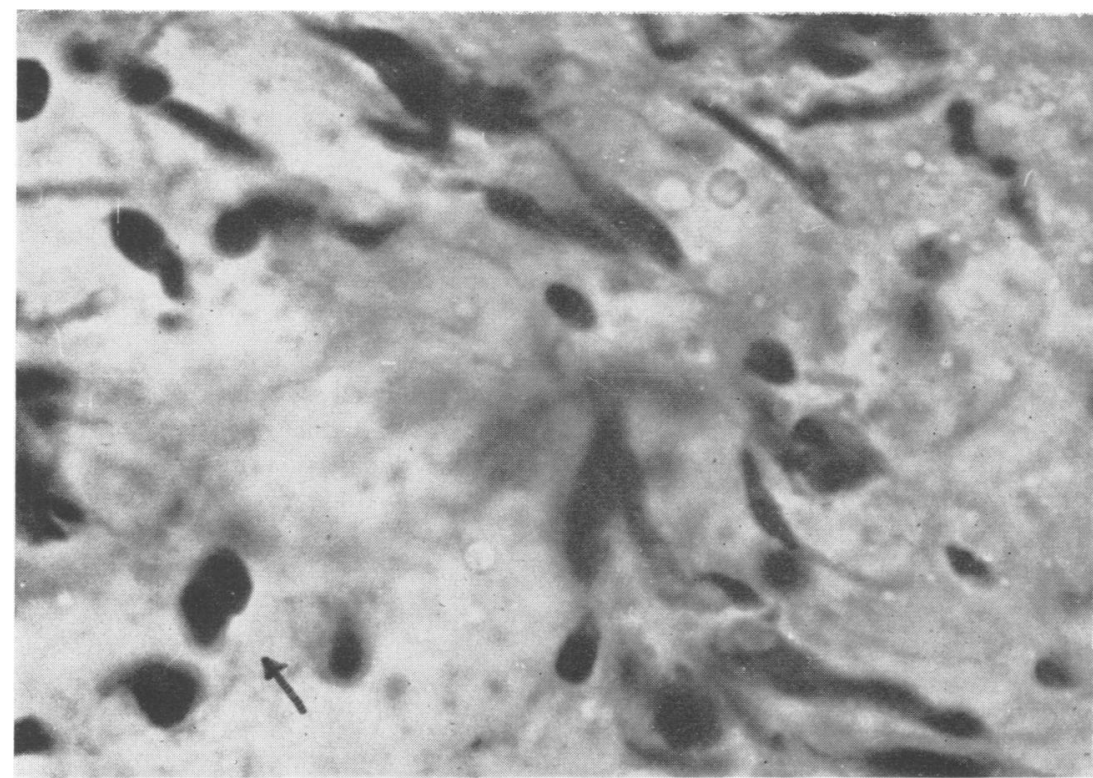

FIG. 8 Biopsy of a skin lesion after exposure of a syphilitic rabbit to $H B O$ for 3 hrs at 3 ATA. Division of mononuclear cell. $\times 600$

In areas where necrosis had developed, an accelerated process of repair and elimination of the damaged tissue indicated by the presence of polynuclear cells and macrophages was established.

The histopathology of biopsies taken from control animals unexposed to HBO showed after the same time the picture of progressive inflammation and destruction. The difference was even more evident 15 and 30 days respectively after exposure to HBO.
The necrotic foci at that time in the animals exposed to HBO displayed in histological preparationso obvious signs of advanced and intensive reparativeo processes with production of newly formed connective tissue (Fig. 9), whereas in the control animalsthe destruction and inflammation (Fig. 10, overleaf) were still progressing or the reparative process was just beginning.

It could also be demonstrated histochemically

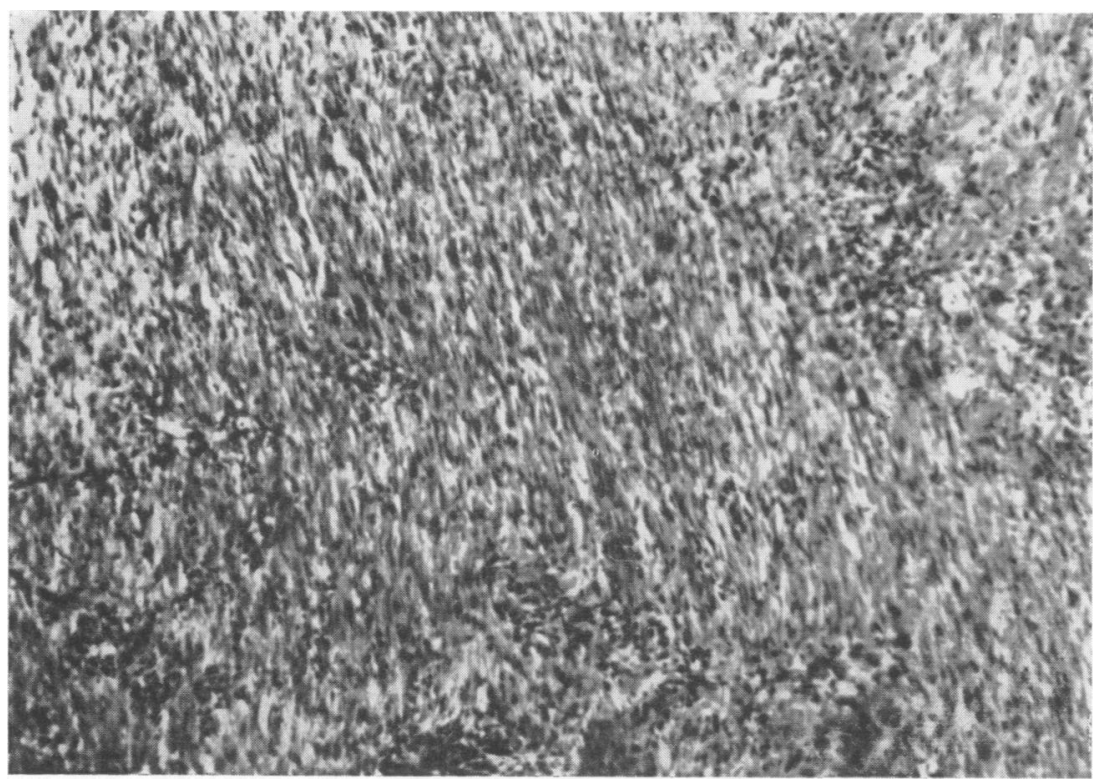

FIG. 9 Biopsy of a skin lesion 15 days after exposure to $H B O$. Intensive reparative activity with production of newly formed connective tissue. $\times 200$ 




FIG. 10 Biopsy of a skin lesion from a control animal not exposed to $\mathrm{HBO}$. Inflammation and progressive tissue destruction. $\times 200$

that the mucoid metachromatic material, which is abundant in the proliferative stage of skin lesions in experimental rabbit syphilis (Turner and Hollander 1957), became markedly reduced after exposure to HBO.

\section{Discussion}

Although the requirement for anaerobiasis of $T$. pallidum is generally accepted, doubts on this belief and on the anti-treponemicidal action of oxygen per se have been expressed (Turner and Hollander, 1957).

It is obvious, from our present knowledge, that $T$. pallidum requires in vitro in survival media an exceptionally low oxidation-reduction potential $(T$. pallidum cannot be cultivated in vitro), but there is very limited and mostly unverified evidence available regarding the need for anaerobiasis of $T$. pallidum in vivo (proliferation of $T$. pallidum in old granulating wounds, predilection for syphilitic lesions at sites of trauma, numerous $T$. pallidum in the macerated syphilitic foetus, etc.), and regarding the influence of oxygenation and the requirements needed (physical or nutritional) for the growth of $T$. pallidum in tissue (Hardy, 1969); Turner and Hollander, 1957; Chesney, 1928; Willcox and Guthe, 1966).

Our experiments on the effect of HBO under various conditions on rabbit syphilis, demonstrated that the toxic influence of oxygen on $T$. pallidum in vivo is not lethal and cannot prevent or abort the infection if the experimental rabbit is exposed in the incubation period to pure oxygen at a tension of 2 to 3 ATA intermittently for up to $30 \mathrm{hrs}$. A longer exposure time and increased tension was in general lethal to the animal itself.

When the infected rabbits were exposed to HBO immediately or shortly after infection but before clinical lesions had developed, the differences between the exposed and control animals were found to be small, but when the animal was exposed to HBO in the exponential stage of infection (Collart, Franceschini, and Durel, 1971), there was an evident stimulatory effect on the defence mechanism and the repair of pathological changes caused by the treponeme.

In contrast, our investigations have shown that suspensions of motile $T$. pallidum in 50 per cent. rabbit serum exposed in vitro to $\mathrm{HBO}$ at 2 and $3 \mathrm{ATA}$ for 20 and $15 \mathrm{~min}$. respectively completely lost their motility.

Clearly there is an essential difference between the oxygen sensitivity of $T$. pallidum in vitro and in the infected animal, but its mode of action is still not well understood.

It is known (Meijne, 1970) that by exposure to $\mathrm{HBO}$ at 3 ATA a rise of about 25 per cent. in $\mathrm{O}_{2}$ content is achieved in the arterial blood, but there is no evidence that an increased $\mathrm{pO}_{2}$ alters the oxygen consumption in tissue cells adequately supplied with oxygen unless oxygen toxicity occurs (Horne, 1965; Telfer and Jennett, 1965).

Nevertheless, our experiments demonstrate that $\mathrm{HBO}$ has a definite effect in syphilitic rabbits. At first $T$. pallidum became less numerous in active lesions after oxygenation and may transiently 
disappear from darkfield preparations. The explanation of this phenomenon can be only speculated upon. It might be supposed with considerable probability that hyperbaric oxygen produces unfavourable conditions for the existence of $T$. pallidum in spiral form, but it retains its virulence and germinative ability in some other more resistant form, which after cessation of the harmful influence of hyperbaric oxygenation, again develops an abundant growth of spiral forms. Such ability of treponemes to produce non-spiral forms under adverse circumstances under the action of penicillin has recently been described in electron microscopic studies (Ovčinnikov and Delektorskij, 1971), and it may be assumed that $\mathrm{HBO}$ is a stressful factor having a similar influence on treponemes in vivo.

At present it cannot be established how far HBO affects $T$. pallidum directly and how far it affects the host defence mechanism which is evidently stimulated by $\mathrm{HBO}$ as proved by histopathological findings in the skin lesions. It appears that the beneficial effect of $\mathrm{HBO}$ on the clinical course of skin lesions seems to be based on the stimulation of cellular and tissue repair activity (increased phagocytosis, reduced inflammation, elimination and repair of damaged tissue, and regeneration) rather than on a direct treponemicidal effect in vivo.

\section{Summary}

An investigation was conducted on the effect of hyperbaric oxygenation (HBO) in experimental rabbit syphilis, assuming that the exposure of infected animals to a high tension of pure oxygen might have a toxic effect similar to that on Treponema pallidum in vitro (which is strictly anaerobic).

The experiments were carried out (including controls) on 64 rabbits, which were inoculated testicularly (36), intravenously (18), or subcutaneously (10) with the pathogenic Nichols strain.

The infected animals were exposed in various tests to $\mathrm{HBO}$, usually at 2 to 3 atmospheres absolute (ATA) for 2 to $4 \mathrm{hrs}$ at intervals of from 2 to $4 \mathrm{hrs}$. The daily exposures varied from one to six and the, total exposure time from 4 to $30 \mathrm{hrs}$.

Rabbits inoculated intratesticularly were exposed to HBO 5 days after inoculation. If clinical manifestations were not already present their onset was postponed (for about 4 weeks), but if clinical lesions had already developed, a transient return to normal could be achieved. In darkfield examinations treponemes became less numerous, and a complete but transient absence of treponemes usually resulted.

HBO could not prevent or abort the infection in animals inoculated intravenously when given im- mediately after inoculation, but when applied later, near the end of the inoculation period, it postponed the appearance of skin lesions.

When skin lesions had already developed, HBO had a distinct stimulative effect on regenerative activity and normalization of the lesions; this could be demonstrated clinically and histopathologically.

Little influence of HBO on the serological tests in the exposed animals could be detected.

The toxic influence of $\mathrm{HBO}$ on $T$. pallidum in vivo under the experimental conditions in these investigations did not prove to be lethal, although a beneficial effect on the lesions in the syphilitic rabbit could be demonstrated. This effect seemed to be caused by stimulation of the host defence mechanism rather than by a directly treponemicidal action.

\section{References}

Boerema, I., and Groeneverd, P. H. A. (1970) In 'Proz. IV Int. Congr. on Hyperbaric Medicine', ed. I. Wada and T. Iwa, p. 255-263. Williams and Wilkins, Baltimore

Chesney, A. M., Turner, T. B., and Halley, C. R. L. (1928) Bull. Fohns Hopk. Hosp., 42, 319

Collart, P., Franceschini, P., and Durel, P. (1971) Brit. F. vener. Dis., 47, 389

HARDY, P. (1969) WHO/INT/VDT/279. Geneva

HoRne, T. (1965) In 'Hyperbaric Oxygenation. Proc. II Int. Congr., Glasgow, 1964', ed. I. McA. Ledingham, p. 44-45. Livingstone, Edinburgh

MeijNe, N. G. (1970) In 'Hyperbaric Oxygen and its Clinical Value: Oxygen under Increased Pressure in Infectious Diseases', p. 185. Thomas, Springfield, Ill.

Ovčinnikov, N. M., and DelektorskiJ, V. V. (1971) Brit. F. vener. Dis., 47, 315

Telfer, A. B. M., and Jennetr, S. M. (1965) In 'Hyperbaric Oxygenation. Proc. II Int. Congr., Glasgow, 1964', ed. I. McA. Ledingham, p. 77. Livingstone, Edinburgh

Turner, T. B., and Hollander, D. H. (1957) 'Biology of the Treponematoses'. Wld Hlth Org. Monogr. Ser. No. 35. WHO, Geneva

Willcox, R. R. and Guthe, T. (1966) Bull. Wld Hlth Org., 35, Suppl. (Treponema pallidum)

Effet de l'hydrogène hyperbare (OHB) dans la syphilis expérimentale du lapin SOMMAIRE

Une recherche a été effectuée sur l'effet de l'oxygénation hyperbare (OHB) dans la syphilis expérimentale du lapin avec l'idée que la soumission d'animaux infectés à une haute tension d'oxygène pur pourait avoir une action toxique in vitro sur Treponema pallidum (qui est anaérobie strict). 
Les essais portèrent (témoins compris) sur 64 lapins inoculés par voie testiculaire (36), intraveineuse (18) ou sous-cutanée (10) avec la souche Nichols pathogène.

Les animaux infectés furent exposés à l'OHB et soumis à des tests variés; l'oxygène fut généralement administré à 2 ou 3 atmosphères (en absolu) (ATA) pendant 2 à 4 heures, à intervalles de 2 à 4 heures. Les expositions quotidiennes allèrent de 1 à 6 et le temps total d'exposition de 4 à 30 heures.

Les lapins inoculés par voie testiculaire furent exposés à l'OHB cinq jours après l'inoculation. Si les manifestations cliniques n'étaient pas déjà apparu, celles-ci furent retardées (d'environ quatre semaines) mais si une lésion clinique s'était déjà developpée, un retour passager à la normale put être obtenu. Au fond noir, le nombre des tréponèmes diminua pour arriver généralement à une absence complète, mais transitoire, de tréponèmes.
L'OHB ne peut pas prévenir ou faire avorter l'infection chez les animaux inoculés par voie intraveineuse lorsqu'il est administré immédiatement après l'inoculation, mais, administré plus tard, vers la fin de la période d'incubation, il retarde l'apparition des lésions cutanées.

Si les lésions cutanées étaient déjà apparues, l'OHB eut une action stimulante nette sur l'activité régénératrice et la normalisation des lésions, comme ceci fut démontré cliniquement et histo-pathologiquement.

On ne put trouver aucune influence de l'OHB sur la sérologie des animaux qui y furent soumis.

L'influence toxique de l'OHB sur les tréponèmes in vivo, dans les conditions expérimentales des présentes recherches n'eut pas d'action létale, bien que l'on put constater un effet benéfique sur les lésions de la syphilis du lapin. Cet effet a semblé être plus dû au mécanisme de défense de l'hôte qu'à une action tréponémicide directe. 